\title{
New Literacies: Some Implications for Language Teachers
}

\author{
Monica Ella Harendita \\ ELESP - Sanata Dharma University \\ monica.harendita@gmail.com
}

\begin{abstract}
The ever-changing development of digital technology has become a scapegoat that exacerbates literacy. In scrutinising this issue, this article counters the simplistic view on literacy. Instead, it views literacy as socially, culturally and historically constructed. Therefore, the traditional definition of literacy, which is the ability to read and write, may not fit the digital age. This article discusses how digital technologies have reshaped the nature of literacy. After discussing literacy, and the Internet in general and Web 2.0 in particular, this paper presents some implications for language teachers in dealing with the "altered" literacy practices. First, critical literacy should be embedded in classroom practices so as to make students critically evaluate the free-flowing information on the Internet. Second, language teachers should nurture participatory culture of the students by encouraging collaboration among them.
\end{abstract}

Keywords: new literacies, digital technology, language teachers

\section{INTRODUCTION}

The vast development of digital technology has influenced many aspects in this contemporary world. Of those aspects, one significant notion that may have been affected is literacy (Gee, 2002). Literacy has undergone a long process throughout history and is seen as a fundamental aspect of education. In the past, literacy was associated mainly with reading and writing, particularly those dealing with printed materials.

The types of literacy practices focusing on reading and writing in print-based materials are worth examining in the digital age in which information is extensive. It becomes more complex with the development of Web 2.0 which allows any Internet users to participate and collaborate in content making. In response to this phenomenon, criticisms viewing that this is threatening literacy have accordingly risen. However, this may not be the case. In fact, the advancement of digital technology such as the Internet has reshaped literacy practices. Consequently, new literacies arising from the ever-changing Internet and Web 2.0 have brought about some important implications for language educators. Thus, this essay will provide a brief elaboration of literacy and Web 2.0, as well as the implications of changed literacy practices that language teachers may consider.

Literacy, which traditionally refers to the ability of reading and writing, may be seen as the foreground which enables knowledge to be obtained and spread within society. Gee and Hayes (2011) identify literacy as a "delivery system for oral language" (p. 15). Although oral language can contribute to information transmission and knowledge development, literacy is the one which provides artefacts in academics. It is through which knowledge can be reserved, referred to, and, as a result, make it possible to transform and develop according to the advances in life.

Literacy serves as one key aspect in educational practices (Hartman, Marsink, \& Zheng, 2010). In some countries across the world, literacy is regarded as "a precondition of successful transition to becoming a postindustrial economy and a knowledge society" (Knobel \& Lankshear, 2011, p. 14). Furthermore, it is not only a concern in educational practices, but also a focus in educational research (Lankshear \& Knobel, 2011). Literacy, therefore, is central to education. 
lliteracy usually signifies deeper implications than the incapability of reading and writing. Graff (2011) argues that "illiteracy is stigma" (p. 24) which means that being literate requires a struggle to acquire the ability to read and write as well as to unstick the label of unworthiness and unproductiveness. It is closely associated with poor and marginalized society (Lankshear \& Knobel, 2011). Nonetheless, there has been a new approach to literacy which sees literacy as social practices that "can only be understood when they are situated within their social, cultural, and historical contexts" (Gee et al., 1996, in Lankshear \& Knobel, 2011, p. 13). Similarly, Graff (2011) supports this sociocultural perspective of literacy by stating that literacy is "historically founded and grounded" (p. 45).

Leu, Kinzer, Coiro, and Cammack (2004) record how socio-historical contexts in the past had an impact on literacy. In different parts of the world, the nature of literacy has been regularly shaped by the changing social forces. Leu et al. (2004) pinpoint the social forces in the medieval age in England and its colonies. At that time, as European churches had undergone post-transformation, resulting in more widespread printed books and texts, particularly the religious ones. Considered as a threat to the autocratic governments, printing presses were then restricted. Another exemplification of the interconnectedness of literacy and social forces can be seen through the case of democracy development in the United States and other countries. The advance of democracy has resulted in the establishment of schools which are expected to 'create' literate people to take part in building the countries and nations (Kaestle, Damon-Moore, Stedmen, Tinsley, \& Trollinger, 1993; Mathews, 1966, as cited in Leu et al., 2004).

Apparently, different social forces have shifted literacy practices. In this era where technology development is enormously increasing, literacy needs to be redefined because seeing literacy as an ability to read and write seems too simplistic. A new and expanded characterization of literacy should take into account some changes that occur in the society and different contexts in which literacy is situated. So as to know how literacy is positioned in this era, the following paragraphs will first briefly describe some types of Web 2.0 before moving to how those types of digital technology have an impact on literacy practices.

\section{THE EMERGING WEB 2.0}

Web 2.0, a more sophisticated term for the-Internet-as-children-and-youngpeople-know-today, retains characteristics which differ from World Wide Web (WWW) or Web 1.0. While Web 1.0 seems to deliver information through one-way communication, this new type of technology allows Internet users to collaborate and participate. Some of Web 2.0 well-known applications include blogs, wikis, and social networking sites. As Graff (2011) states that literacy itself has changed in regard to its environment. Thus, in order to examine what is changing, it is essential to see the nature of the three abovementioned online environments.

Blogs are short for weblogs or in a literal meaning can be "a log or record of information presented as a date-ordered template" (Davies \& Merchant, 2009, p. 84). According to Lankshear and Knobel (2011), blogs were first introduced in early 1990's, "as websites listing annotated hyperlinks to other websites" (p. 144). They further state that blogs were initially used to allow bloggers to introduce other interesting sources to other Internet users by putting the links on their blogs. However, in this digital era, people can have diverse purposes for writing on blogs. Brooks (2008) points out that blogs have "become a form of confessional where anyone and everyone spills the beans on their work, relationships, schoolteachers, parents and themselves" (p. 23). In this sense, blogs may also serve as a reflective journal or a diary.

The next application which will be briefly discussed is wikis. A wiki, according to Lankshear and Knobel (2011) is "a collection of webpages whose content is typically organized around a particular purpose, topic, or theme" (p. 157). Wikipedia, as an example of wikis, 
seems to be the most well-known encyclopaedia in the Internet. The registered users of Wikipedia are able to write and edit the entries. While general websites are usually under a certain person's or group's control, a wiki's content is not controlled by a webmaster (Lankshear \& Knobel, 2011). Therefore, wikis seem to be one channel in which users can actively participate in knowledge production and/or sharing.

Another type of Web 2.0 application which may be very popular, particularly among young people, is social networking sites (SNS). SNS, such as Facebook and MySpace, are "digital spaces or platforms formally dedicated to facilitating a range of connections between people" (Lankshear \& Knobel, 2011, p. 182). Boyd and Ellison (2007) in Griffith and Liyanage (2008) list several shared features that Facebook and Myspace have, including constructing a profile, providing a list of connected users, and viewing as well as crisscrossing the list of connections with the other users. Moreover, through SNS, Internet users can set up online communities and create affinity space (Gee \& Hayes, 2011) where they can meet people of the same interests.

\section{IMPLICATIONS OF THE EMERGING WEB 2.0 AND NEW LITERACIES FOR LANGUAGE TEACHERS}

Despite various manifestations of literacy practices using the Internet and Web 2.0 technologies, Fasher-Herro and Steinkuehler (2009) point out that literacy is still seen as being able to be measured through written texts and conventional reading programs. They further state that schools in the US have increased the amount of time to teach reading and writing to the grade four students, yet, the reading literacy has not improved. This is similar to what Hartman, et al. 2010 point out, stating that the decline in reading assessment is seen as crisis in the US. Technology, alas, has been claimed as one of the triggering causes. It is incontestable that the growing technology has imposed some bad effects on some literacy practices. However, this is may not be a real crisis since it is not supported by empirical evidence and the assumption seems to overlook the development of computer technology which results in changed mode of communication (Hartman, et al., 2010).

To some points, the affordances of Web 2.0 have altered the way that students learn. In this context, students refer to generation $Y$ and $Z$ (Brooks, 2008) or digital natives (Prensky, 2001), who were born in the era where technology innovations have extensively and significantly affected social life and thus enable them to acquire the technological skills naturally. Closely attached to learning, literacy practices have also diverged in regards to the shift from printbased materials to digital materials.

Traditional literacy practices may not fit in anymore in this era. In this era of technology, "young people need to become capable and competent users of both print and other forms of meaning enabled by new technologies" (Kalantzis, Cope, \& Cloonan, 2010, pp. 61-62). It thus has broadened the literacy concept "to not only include traditional literacies, reading and writing print text for example, but also reflect the needs of students living and learning in a digital world" (Sylvester \& Greenidge, 2009, p. 284). This new concept suggests the diverse types of literacy and the predisposition to see literacy as multiple. Accordingly, a term like 'new literacies' or 'multiple literacies' have been coined to refer to different types of literacies in the digital age. As much as the time the students invest in their practices outside the classroom, the implications have not been widely considered in classroom literacy practices. In light of this, there should be some considerations, such as encouraging critical literacy and participation, to be taken in classroom literacy practices in order that the students can contribute in contemporary society.

Educators should encourage students' critical literacy due to some critiques on the openness of Web 2.0 which has made it possible for any users to create content and speak their voice via Web 2.0 tools. Consequently, the ample information in the Internet has resulted in 
knowledge overflow which may make students overwhelmed. On the one hand, it can provide them with useful information that they really need. On the other hand, too much information may lead to confusion as some may be irrelevant to what they are actually trying to search.

Moreover, interactivity and openness may be the most salient characteristics of Web 2.0. As a result, many Internet users are able to use the online spaces to freely create and share particular contents, such as writing, images, sounds, and videos without being concerned about their expertise in certain fields. Accordingly, they can produce knowledge and many of them are becoming 'pro-ams' or professional amateurs (Gee \& Hayes, 2011). Thus, other issues rising along with the development of Web 2.0 are accuracy and authors' expertise, e. g. in Wikis (Carrington, 2009). Besides, another aspect that might need to be highlighted is the neutrality of information. Online texts may be tendentiously written to accommodate certain purposes, particularly related to commercial or political drives.

Therefore, considering the overflowing information, the concern about accuracy, credibility, and neutrality of information, there is a growing need to accommodate critical literacy in classroom literacy practices which may differ from that of traditional printed materials. In the same vein, Sylvester and Greenidge (2009) argue that "the Internet has initiated critical reading skills not typically required in traditional texts" (p. 284). Critical reading will help the students to be able to evaluate the relevance as well as the accuracy and reliability of the information. Any power relation influencing how certain information is delivered, which might include the political, economic and ideological interests (Selwyn, 2009, in Asselin \& Moayeri, 2011), can also be uncovered through critical evaluation. Online critical literacy may assist the students to become aware of neutrality by, for example, examining the sites if they are affiliated with particular political groups or companies to notice any biased perspectives.
Furthermore, critical literacy is needed in facing the ubiquity of hyperlinks that have been claimed to make Internet users read superficially without going into deeper level of reading (Carrington, 2009). Compared to printed materials requiring readers to go through the texts to be able to make sense of what is written, the presence of hyperlinks in online texts enables the readers to easily navigate to other related information even before they have not finished reading the whole texts. Literacy therefore becomes jeopardized if Internet users read superficially and think that they already comprehend something well. In light of this, being critical is also essential to prevent students from reading superficially and may bring them closer to indepth understanding.

In addition, in nature, printed materials retain a number of differences from online texts. Rarely are website contents written in a plain text without being added by images, hyperlinks, and videos. Due to this rich type of texts, online texts have been multimodal, requiring different skills in reading the information. Kress (2003) in Fasher-Herro and Steinkuehler (2009) argue that "books simply cannot provide the same level of multimodal production" (p. 56). It becomes more multifaceted when taking multimodal texts into account, implying the need to consider the images, videos, and sounds embedded in the text. Therefore, reading in the contemporary world takes up critical, visual, and traditional literacy to be addressed in classroom literacy practices (Brooks, 2008).

Another aspect which needs attention is the nature of Web 2.0 which opens the gate of participatory culture. Rather than merely envisaging students as consumers of information, new literacies view students as producer of knowledge. Web 2.0 has also challenged the conventional idea of teacher as a "gatekeeper of knowledge" (Fahser-Herro \& Steinkuehler, 2009, p. 55) as anyone can contribute to knowledge production and sharing. In view of that, power relation between student-teacher is also distinct from that of traditional classrooms (Asselin \& Moayeri, 2011) because students themselves can be the teachers of their peers. 
Similarly, Fahser-Herro and Steinkuehler (2009) point out that "literacy practices surrounding Web 2.0 technologies call for knowledge construction in a collaborative, production-oriented, somewhat nonlinear manner with access to knowledge mediated by its users" (p. 56). Accordingly, there should be a shift in viewing knowledge from individual intelligence to collective intelligence (Lankshear \& Knobel, 2006, in Asselin \& Moayeri, 2011). Students should be encouraged and facilitated to actively participate and collaborate with other students in order to produce and share information.

Although the role of teachers in classroom practices tends to change, Leu, Kinzer, Coiro, and Cammack (2004) emphasise that their roles are becoming more important. Teachers should be aware of the new forms of literacy developing among students and embrace the practices. It is also pivotal to note that physical presence of computers or gadgets will not necessarily guarantee that a class has embarked on a pedagogy based on the new literacies perspective. Therefore, selfreflection questions should be addressed to language teachers whether they have facilitated literacy practices which encourage students to participate and collaborate in the emerging Web 2.0. Familiarizing students with type of Web 2.0 technologies and giving them sufficient time to explore it can be the starting point before students plunge into participatory culture, in which they do not merely consume Web 2.0 but also contribute to its development. Some practices that might be done include creating or editing blog's content, and video-making through which they can work together with their peers to create a particular project and then publish it so they can share it with other students elsewhere.

Consequently, in order to be able to assist students in working with Web 2.0 technologies, teachers have to experience and gain some background knowledge of how the technologies work. Teachers' exploration and familiarisation with the technologies may also uncover what aspects can prevail or fail to support certain learning practices. Nonetheless, there has been a concern about the technology gap between teachers and students (Fahser-Herro \& Steinkuehler, 2009). According to the National Center for Education Statistics (NCES) 2009, in the US, some important issues for educators include access and Internet connection speed (in FahserHerro \& Steinkuehler, 2009. These matters, thus, should be addressed along with the incorporation of digital literacy practices in the classroom.

\section{CONCLUDING REMARKS}

On the whole, it can be seen that the Internet has a significant impact on the society and education, particularly on literacy which is central to education. Literacy practices have shifted from traditional to digital ones along with the development of the Internet and Web 2.0. As a result, the word 'new' has been attached to the word literacies denoting a perspective in seeing literacy.

This essay has attempted to provide implications for language teachers, particularly that of reading and writing, to assist students in contributing in knowledge society. First, critical literacy should be embedded in classroom practices so as to make students critically evaluate the free-flowing information on the Internet. Second, language teachers should nurture participatory culture of the students by encouraging collaboration among them.

Yet, positive views around the benefits of the Internet and Web 2.0 technologies to literacy practices cannot stand alone without acknowledging the jeopardy that they may retain. As a matter of fact, there are some other issues closely related to the growth of technologies, such as cyber safety and copyright. Therefore, it also becomes the responsibilities of teachers to have a profound understanding of how technologies work and what might put students into risk to be able to assist them to make the most of their being online. 


\section{REFERENCES}

Asselin, M., \& Moayeri, M. (2011). The participatory classroom: Web 2.0 in the classroom. Literacy Learning: the Middle Years, 19(2), i-vii. Retrieved March 20, 2012 from http://go.galegroup.com/ps/i.do?id=GALE\%7CA259959929\&v=2.1\&u=monash\&it=r\&p=AONE\& $\mathrm{sw}=\mathrm{w}$

Brooks, K. (2008). An impossible passion: young people, contemporary popular culture and reading. Access, 22(3), 19-28. Retrieved March 15, 2012 from http://search.informit.com.au/fullText;res=AEIPT;dn=172002

Carrington, V. (2009). From Wikipedia to the humble classroom wiki: why we should pay attention to wikis. In V. Carrington \& M. Robinson (Eds.), Digital literacies: social learning and classroom practices (pp. 65-79). London: Sage Publications Ltd.

Davies, J., \& Merchant, G. (2009). Negotiating the blogosphere: educational possibilities. In V. Carrington \& M. Robinson (Eds.), Digital literacies: Social learning and classroom practices (pp. 81-93). London: Sage Publications Ltd.

Fahser-Herro, D., \& Steinkuehler, C. (2009). Web 2.0 literacy and secondary teacher education. Journal of Computing in Teacher Education, 26(2), 55-62. Retrieved March 20, 2012 from http://go.galegroup.com/ps/i.do?id=GALE\%7CA215514784\&v=2.1\&u=monash\&it=r\&p=AONE\& $\mathrm{sw}=\mathrm{w}$

Gee, J. P. (2002). New times and new literacies. In M. Kalantzis, G. Varnava-Skoura, \& B. Cope (Eds.), Learning for the future: new worlds, new literacies, new learning, new people. Australia: Common Ground Publishing Pty Ltd.

Gee, J. P. \& Hayes, E. R. (2011). Language and learning in the digital age. New York: Routledge.

Graff, H. J. (2011). Literacy myths, legacies, and lessons: new studies on literacy. New Brunswick, New Jersey: Transaction Publishers.

Griffith, S, \& Liyanage, L. (2008). An introduction to the potential of social networking sites in education. In I. Olney, G. Lefoe, J. Mantei, \& J. Herrington (Eds.), Proceedings of the Second Emerging Technologies Conference 2008 (pp. 76-81). Wollongong: University of Wollongong.

Hartman, D. K., Morsink, P. M., \& Zheng, J. (2010). From print to pixels: the evolution of cognitive conceptions of reading comprehension. In E. A. Baker (Ed.), The new literacies: multiple perspectives on research and practice (pp. 131-164). New York: Guilford Press.

Kalantzis, M. Cope, B. \& Cloonan, A. (2010). A multiliteracies perspective on the new literacies. In E. A. Baker (Ed.). The new literacies: multiple perspectives on research and practice (pp. 131-164). New York: Guilford Press.

Lankshear, C. \& Knobel, M. (2011). New literacies: everyday practices and social learning. Berkshire: McGraw Hill \& Open University Press.

Leu, D.J., Kinzer, C.K., Coiro, J.L., \& Cammack, D. W. (2004). Toward a theory of new literacies emerging from the Internet and other information and communication technologies. In Theoretical Models and Processes of Reading. (5th ed.). International Reading Association.

Prensky, M. (2001). Digital natives, digital immigrants. On the Horizon, 9(5): 1-6. Retrieved March 17, 2012 from http://www.scribd.com/doc/9799/Prensky-Digital-Natives-Digital-Immigrants-Part1

Sylvester, R. \& Greenidge, W. (2009). Digital storytelling: extending potential for struggling writers. The Reading Teacher, 63(4), 284-295. DOI: 10.1598/RT.63.4.3 